\title{
FORMULATION, EVALUATION, AND IN VIVO ANTI-INFLAMMATORY AND ANTI-ARTHRITIC ACTIVITIES OF MORINGA GRANULES
}

\section{HARITH JAMEEL MAHDI ALSAMMARRAIE ${ }^{*}$, NURZALINA ABDUL KARIM KHAN², ROZIAHANIM MAHMUD ${ }^{3}$}

${ }^{*}$ Department of Applied Chemistry, Faculty of Applied Sciences, University of Samarra, Iraq, ${ }^{2}$ Discipline of Pharmaceutical Technology, School of Pharmaceutical Sciences, USM, Malaysia, ${ }^{3}$ Discipline of Pharmaceutical Chemistry, School of Pharmaceutical Sciences, USM, Penang, Malaysia

Email: ph.harith75@gmail.com

Received: 12 Dec 2020, Revised and Accepted: 17 Feb 2021

\section{ABSTRACT}

Objective: Consumption of crude natural products like plants and herbs for mitigation or treatment of illnesses usually accompanied with inconsistent therapeutic effects because of poor solubility and low bioavailability of active phytochemical(s) in addition to product instability. To overcome all of above mentioned drawback ethanol extract of Moringa oleifera leaf was formulated as standardised solid dosage form.

Methods: Different types of materials as an adsorbent, surfactant and other necessary excipients were tested to be use in formulation of Moringa granules utilising wet granulation method. The formulated Moringa granules was then evaluated for organoleptic properties and physical characteristics, in vitro dissolution test, compatibility, drug content, heavy metal tests and microbial limit tests. Additionally, the in vivo antiinflammatory against Carrageenan-induced paw oedema and anti-arthritic activity against CFA-induced arthritis were also assessed.

Results: 95\% ethanol extract of M. oleifera leaves was successfully formulated as standardised granules for oral administration utilising simple and lowcost techniques. Dissolution rate for the marker compounds was increased by an average of 1.076 fold. Animal groups given the prepared Moringa granules showed an improvement in the anti-inflammatory activity and the anti-arthritic activity compared to animal groups given crude extract at the same dose level. Additionally, all the treatment groups showed a significant difference at $\mathrm{P}<0.05$ and $\mathrm{P}<0.01$ compared to control group.

Conclusion: To the best of our knowledge, this work was the first to use gum Arabic in the formulation of a standardised botanical pharmaceutical dosage form of M. oleifera crude extract. Additionally, formulation of Moringa granules apparently improves the drug release profile and bioactivity compare to Crude Moringa extract.

Keywords: Moringa oleifera, Moringa granules, Organoleptic properties, Anti-inflammatory, Anti-arthritic

(C) 2021 The Authors. Published by Innovare Academic Sciences Pvt Ltd. This is an open access article under the CC BY license (https://creativecommons.org/licenses/by/4.0/) DOI: https://dx.doi.org/10.22159/ijap.2021v13i3.40478. Journal homepage: https://innovareacademics.in/journals/index.php/ijap

\section{INTRODUCTION}

The interest in botanical products has been regenerated because of the discovery of many novel natural bioactive phytochemicals [1]. However, the therapeutic potential of these compounds is often limited by their poor solubility, low bioavailability and product instability [2]. In this regard, pharmaceutical scientists should explore delivery systems that can enhance drug solubility and bioavailability and improve product stability. The complexity of phytoconstituents and the indecision about the phytochemical(s) responsible for bioactivity are the most challenging problems in formulation and evaluation of herbal products.

Moringa oleifera Lam is well-known and most widely cultivated species of Moringaceae, which is a mono-generic flowering plant family that comprises 13 species. M. oleifera has been founded in many tropic and sub-tropic regions worldwide. The plant is referred to by a number of names such as horseradish tree, drumstick tree, ben oil tree, miracle tree, and "Mother's Best Friend". The leaf of $M$. oleifera is the most valuable part of the plant used as food and traditional medicine source. Large number of nutrients as such proteins, minerals and fibres that affords an important role in the human diet as well as it is a valuable nutritive, healing and socioeconomic potentials [3]. An online survey indicates a large number of $M$. oleifera medicinal and dietary supplement products, alone or in herbal combinations, available in the global markets. The products are mostly in oral dosage form as tablets, capsules, tea bags, elixir, syrup and leaf powder for decoction. Our survey and that conducted by [4] revealed that almost all of the reviewed products shared one or more features of the following variable in product composition, not standardised against a bioactive phytochemical marker(s) and inconsistence in medicinal indications and uses despite originating from the same plant part and using the same dose strength and same manufacturing processes.
In this study, an ethanol extract of M. oleifera leaves had been formulated as a standardised granules, evaluated for their organoleptic properties, physical and chemical characteristics, and subjected to in vitro dissolution test. Additionally, in vivo bioactivity of the formulated granules as anti-arthritis and antinociceptive were also evaluated. To the best of our knowledge, this the first time that ethanol extract of Moringa oleifera leaves was formulated as a solid dosage form with standardised content of marker compounds, standardised drug release rate and improved bioactivity.

\section{MATERIALS AND METHODS}

Chemicals and reagents

Astragalin (Kaempferol-3-O-glucoside) 98\% purity, Extrasynthese (Genay, France); Cryptochlorogenic acid (4-O-Caffeoylquinic acid) 98\% purity, Chemfaces (Wuhan, China); Ethanol 95\%, Fisher Scientific (Selangor, Malaysia). $\lambda$-Carrageenan, Indomethacin, Complete Freund's Adjuvant (CFA) $(1 \mathrm{mg} / \mathrm{ml})$ of heat killed dried M. tuberculosis (strain H37Ra, ATCC 25177) suspended in $1.5 \mathrm{ml}$ mannide monooleate and $8.5 \mathrm{ml}$, and Tween (Polysorbate) 20, 40, and 80all purchased from Sigma-Aldrich, St., MO, USA. Gum Arabic and HPMC, Methocel K100M CR were purchased from Colorcon Ltd, New Hampshire, USA. Magnesium stearate, RandM Marketing, Essex, UK; Microcrystalline cellulose (Avicel PH200) 200, FMC BioPolymer, Newark DE, USA.

\section{Equipment and instruments}

BUCHI R-114 rotary vacuum evaporator, BUCHI Labortechnik AG (Flawil, Switzerland); Drying oven, Memmert GmbH and Co. (Schwabach, Germany); Shimadzu HPLC system, Shimadzu Corporation (Kyoto, Japan); Digital micrometer, Mitutoyo, IDC1012EXBS, Kawasaki, Japan; Electrolab ETD-1020 Tap Density 
Tester (Globe-Pharma) Ireland; Fourier-transform infrared spectrometer Thermo Nicolet Nexus 470, USA.

\section{Authentication of plant materials}

The plant was authenticated by Dr. R. Zakaria, Plant Sciences; and sample was reserved in the herbarium of the School of Biological Sciences, Universiti Sains Malaysia (USM) under a voucher specimen No. 11626

\section{Formulation of Moringa granules (Moringa-G)}

The $95 \%$ ethanol extract of $M$. oleifera leaves prepared by maceration of dried, pulverised leaves in 95\% ethanol at ratio of 1:5 and temperature of $45{ }^{\circ} \mathrm{C}$ for $72 \mathrm{~h}$. The collected extract was first filtered using Whatman No.1 filter paper, concentrated using rotary evaporator then dried in drying oven at $45^{\circ} \mathrm{C}$ for $48 \mathrm{~h}$. The obtained dry extract was formulated as common granules using wet granulation method. Selection of surfactant and adsorbent agent were based on the results obtained from preformulation studies of $95 \%$ ethanol extract of M. oleifera leaves [5]. Ethanol (95\% v/v) was used as wetting agent enough to made Moringa extract as a paste. Tween 20 and gum Arabic were added and kneaded. The prepared mixture then speared on stainless steel tray and dried in drying oven at $45^{\circ} \mathrm{C}$ for $48 \mathrm{~h}$. The dried mass was screened through sieve No.22 $(0.8 \mathrm{~mm})$ and dried again in drying oven at $45^{\circ} \mathrm{C}$ for $24 \mathrm{~h}$ and screened through sieve No. $35(0.5 \mathrm{~mm})$. The collected granules then evaluated.

\section{Organoleptic properties and physical characteristics}

The formulated Moringa-G were evaluated for their organoleptic properties, namely, appearance, colour, odour and taste. Particle size distribution was assessed using the sieve method. Loss on drying at $65{ }^{\circ} \mathrm{C}$, the $\mathrm{pH}$ of $1 \%(\mathrm{w} / \mathrm{v})$ solution at $25^{\circ} \mathrm{C}$ and reconstitution time were determined as described by [6].

\section{Angle of repose}

A stainless-steel funnel with a $10 \mathrm{~mm}$ orifice diameter and $111 \mathrm{~mm}$ length from the top to the end of the orifice was fixed at $4 \mathrm{~cm}$ from the bench to the funnel orifice. In brief, $5 \mathrm{~g}$ of powder sample was charged into the funnel and allowed to fall. The height $(h)$ and width $(w)$ of the pile were measured. The results were considered valid only when a symmetric cone was obtained. The procedure was repeated in triplicate. Angle of repose $(\theta)$ was calculated as follows:

$$
\theta=\tan ^{-1}\left(\frac{h}{0.5 w}\right) \ldots \ldots . E q .(1)
$$

\section{Bulk density and tapped density}

In brief, $10 \mathrm{~g}$ sample was transferred into a $25 \mathrm{ml}$ graduated cylinder with $0.5 \mathrm{ml}$ mark. The cylinder was manually tapped gently twice on a table top surface, and the volume was measured. Bulk density was calculated as follows:

$$
\text { pbulk }=\frac{\mathrm{w}}{\mathrm{vb}} \text {.......... Eq. (2) }
$$

Where $w$ is the weight of the sample, and $V_{b}$ is the volume occupied by the bulk powder.

The cylinder was fixed to the tap density tester and subjected to 500 , 750 and 1250 taps at a rate of 250 taps/min. After each specified number of taps, the tapped volume was measured. Tapped density was calculated as follows:

$$
\text { ptapped }=\frac{\mathrm{w}}{\mathrm{vt}} \ldots \ldots \ldots . . . \text { Eq. (3) }
$$

Where $w$ is the weight of the sample, and $V_{t}$ is the volume occupied by the powder after tapping.

\section{Carr's compressibility index and Hausner's ratio}

The results of bulk and tapped densities were used to calculate Carr's compressibility index (Eq. 4) and Hausner's ratio (Eq. 5). These parameters help in estimating the flow properties and compressibility of the powder.

$$
\begin{aligned}
& \mathrm{CI}=\frac{\text { ptapped }- \text { pbulk }}{\rho \text { tapped }} \times 100 \ldots \ldots \ldots . . . \text { Eq. (4) } \\
& \text { Hausner's ratio }=\frac{\rho \text { tapped }}{\rho \text { bulk }} \text {.. Eq. (5) }
\end{aligned}
$$

\section{In vitro drug dissolution and drug release profile}

In vitro drug dissolution was determined using USP-apparatus II (paddle apparatus). The samples of Moringa-G and M. oleifera crude extract were immersed in $500 \mathrm{ml}$ of distilled water as dissolution medium at $37 \pm 0.5$ ${ }^{\circ} \mathrm{C}$ and paddle speed of 100 revolutions per minute. Six dosage units were individually placed in each of the six vessels of the dissolution apparatus. Aliquots of the dissolution medium $(3 \mathrm{ml})$ from each of the six vessels were withdrawn on $5,15,30,45,60,90,120$ and $180 \mathrm{~min}$ combined and filtered with a $0.45 \mathrm{~mm}$ syringe filter to achieve a pooled sample that will be used as test samples. The volume of the dissolution medium was kept constant by adding $3 \mathrm{ml}$ of the solution pre-heated to $37^{\circ} \mathrm{C}$ to fresh distilled water after each withdrawal. The samples were analysed for drug concentration using HPLC method described by [5]. Percent cumulative drug release for Moringa-G and M. oleifera crude extract were calculated and plotted against time. Graphical analysis method was used for comparison of the dissolution pattern, and the reference markers concentrations at each time point were used to compare the extent of dissolution. Percent dissolution efficiency (\%DE) was used to characterise the release profile. DE can be calculated using the following equation:

$$
\mathrm{DE} \%=\left[\frac{\int_{\mathrm{t} 1}^{\mathrm{t} 2} \mathrm{y} \times \mathrm{dt}}{\mathrm{y} 100 \times(\mathrm{t} 2-\mathrm{t} 1)}\right] \times 100 . . \text { Eq. (6) }
$$

Where $y$ is the percent dissolved reference marker at specified time and $y_{100}$ is the maximum dissolution percent.

\section{Compatibility of excipients}

Fourier-transform infrared (FT-IR) spectroscopy analysis of 95\% ethanol extract of M. oleifera leaves and formulated Moringa-G were conducted to evaluate drug-excipient compatibility. In brief, a $1 \%$ mixture of $95 \%$ ethanol extract of M. oleifera leaves/Moringa-G with IR-grade potassium chloride was prepared as disc and analysed by FT-IR spectroscopy with single-reflection ATR attachment within the IR range of $400 \mathrm{~cm}^{-1}$ to $3000 \mathrm{~cm}^{-1}$.

\section{Drug content}

Drug content was calculated using HPLC method described by [4]. The test solution was prepared by accurately weighed a portion of prepared Moringa-G equivalent to $100 \mathrm{mg}$ of M. oleifera extract, dissolved in $10 \mathrm{ml}$ of $50 \%$ methanol, sonicated and filtered using $0.45 \mathrm{~mm}$ syringe filter to obtain $10 \mathrm{mg} / \mathrm{ml}$ solution. A standard calibration curve was plotted and mean drug content (\%) was calculated as the average of three determinations $(n=3)$.

\section{Microbial limit tests}

Microbial limit test was conducted to quantitatively estimate the total number of aerobic microorganisms, total yeasts and moulds, biletolerated Gram-negative bacteria, Salmonella sp., Escherichia coli, Staphylococcus aureus and Pseudomonas aeruginosa in accordance with [7], Appendix XVIB. The test microbes used in determination of microbial limit test were obtained from School of Biology, USM, Malaysia.

\section{Heavy metals test}

Heavy metal analysis was conducted as described by [7], Appendix IID. Inductively coupled plasma-atomic emission spectroscopy (ICPAES) technique was used to determine the levels of cadmium, arsenic, lead and mercury.

\section{Animal ethics and laboratory animal}

Animal's experimental protocol was approved by Animal Ethics Committee of Universiti Sains Malaysia No.: USM/Animal Ethics Approval/2016/(103) (764) and USM/Animal Ethics Approval/2016/(103)(807). Healthy male Sprague-Dawley rats 8$10 \mathrm{w}$ old and weighing 150-180 g were used. They were fed with standard pellet diet and free access to water. They were housed in polypropylene cages, 3 animals per cage maintained under 12 hour 
light, 12 hour dark cycle; $27 \pm 3^{\circ} \mathrm{C}, 45 \% \pm 5 \%$ relative humidity and allowed to acclimatise for $7 \mathrm{~d}$ before starting the experiments.

\section{In vivo anti-inflammatory activity}

The anti-inflammatory activity of Moringa-G was assessed using Carrageenan-induced paw oedema method and the selection of the administered dose was as described by [8]. The animals were fasted $12 \mathrm{~h}$ before experiment, but provided with water ad libitum. The rats were randomly assigned into four groups of six animals each $(n=6)$, weighed and numbered. Group I was the disease control group given only distilled water. Group II was orally treated with indomethacin ( $5 \mathrm{mg} / \mathrm{kg}$ body weight). Group III was orally treated with M. oleifera crude extract at a dose of $250 \mathrm{mg} / \mathrm{kg}$ body weight and group IV was orally treated with Moringa-G at dose equivalent to $250 \mathrm{mg} / \mathrm{kg}$ body weight. After $1 \mathrm{~h}$ of oral dose treatment, inflammatory paw oedema was induced by injecting $0.1 \mathrm{ml}$ of freshly prepared $1 \%(\mathrm{w} / \mathrm{v})$ carrageenan in normal saline into the sub-plantar region of the left hind paw of the rats. The thickness of the left hind paw was measured using a digital micrometre immediately before and at 1,2 , 3,4 and $5 \mathrm{~h}$ after the carrageenan injection. The anti-inflammatory activity of M. oleifera crude extract and Moringa-G were calculated as percent increase in paw oedema by using the formula:

$$
\% \text { increase in paw oedema }=\frac{A-B}{B} \times 100 \ldots \ldots \ldots . . . \text { Eq. (7) }
$$

Where $A$ is the paw thickness at the respective hours, and $B$ is the paw thickness at hour 0 of the experiment. The results were expressed as mean \% oedema \pm standard error of the mean (SEM) of six animals per group and statistically analysed compared with the disease control group.

\section{In vivo activity against CFA-induced rheumatoid arthritis}

\section{Animals and experimental design}

The animals were randomly designed into five groups of five animals per group $(\mathrm{n}=6)$. Group I: (Normal control) without CFA injection and treatment; group II: (CFA-control) CFA injection and vehicle 10 $\mathrm{ml} / \mathrm{kg} /$ day; group III: CFA injection and oral treatment with indomethacin at $2.5 \mathrm{mg} / \mathrm{kg} /$ day; group IV: CFA injection and oral treatment with $250 \mathrm{mg} / \mathrm{kg} /$ day M. oleifera extract and group V: CFA injection and orally treated with Moringa-G at dose equivalent to $250 \mathrm{mg} / \mathrm{kg} /$ day. The daily oral dose for groups II to $\mathrm{V}$ were administered at 9 am and continued to day 21 post-injection. Measurements were conducted at $2 \mathrm{pm}$.

\section{Induction of arthritis}

Immunological arthritis was induced using the method described by [9]. The hind limbs of rats in groups II to $\mathrm{V}$ were shaved and sterilised with $70 \%$ (v/v) alcohol. Subsequently, $0.1 \mathrm{ml}$ of CFA containing $1 \mathrm{mg} / \mathrm{ml}$ heat-killed $M$. tuberculosis were injected into the sub-plantar area of the left hind paw of each animal under mild anaesthesia with diethyl ether. The time of CFA injection was referred to as day 0 .

\section{Assessment of rheumatoid arthritis}

\section{CFA-induced arthritic paw oedema}

The thickness of the left and right hind paws was recorded on day 0 before the induction of arthritis with CFA and considered as a baseline. The thickness of the paws was measured again on days 3,6 , $9,12,15,18$ and 21 post-CFA injection using a digital micrometre gauge. The percent increase in paw oedema was calculated using equation (7).

\section{Change in animal's body weight}

The body weight of the animals was monitored starting from day 0 and repeated on days $3,6,9,12,15,18$ and 21 post-CFA injection. Percent weight change was calculated using the following formula:

$$
\% \text { weight change }=\frac{\mathrm{Wt}-\mathrm{Wo}}{\mathrm{Wt}} \times 100
$$

Where $W_{t}$ is the weight of the animal at time $t$, and $W_{o}$ is the weight of the animal on day 0 . The calculated weight change in the treatment groups was statistically compared with those in normal control and CFA-control groups.

\section{Arthritic index}

Arthritic index is a numeric system used to score the severity and disease progression of CFA-induced immunological arthritis. Development and severity of induced RA in rats were evaluated by a visual scoring system of the clinical signs and symptoms on a scale of $0-4$ per limb by using the method described by [10] where 0 : no change, 1: slight swelling and erythema of the finger, 2: swelling of the phalanx joint and digits, 3: severe swelling of the entire paws, and 4: deformity or ankylosis. The scores for the left and right hind limbs were combined, and the maximum score was 8. A score of 1 and above indicates arthritis. Measurement was started on day 3 post-CFA injection to avoid the pre-acute phase of CFA and then repeated on days $6,9,12,15,18$ and 21 postinjection.

\section{Walking track analysis}

Walking track analysis was initially described by [11] as an approach to analyse changes in locomotion and functional behaviour. The footprints of each rat were recorded by immersing their hind paws in the ink and allowing them to walk over a paper sheet ( $8.7 \mathrm{~cm}$ wide by $43 \mathrm{~cm}$ long) fixed on a confined walkway corridor, with a dark shelter at the end. After two or three conditioning trials, when the rats were often stopped to explore the corridor, they began to walk steadily to the dark shelter end. The procedure was repeated on day 0 before CFA injection and on days 14 and 21 post-injection. The obtained data from the rat's footprint were used to calculate the functional index (FI) by using the following equation:

$$
\mathrm{FI}=\left[\left(\frac{\mathrm{ETOF}-\mathrm{NTOF}}{\mathrm{NTOF}}\right)+\left(\frac{\mathrm{NPL}-\mathrm{EPL}}{\mathrm{EPL}}\right)+\left(\frac{\mathrm{ETS}-\mathrm{NTS}}{\mathrm{NTS}}\right)+\left(\frac{\mathrm{EIT}-\mathrm{NIT}}{\mathrm{NIT}}\right)\right] \times \frac{220}{4}
$$

where ETOF and NTOF are experimental (injected paw) and normal paw distance, respectively, to the opposite foot (mm); EPL and NPL are experimental and normal paw print length $(\mathrm{mm})$, respectively; ETS and NTS are experimental and normal total paw spreading $(\mathrm{mm})$, respectively; and EIT and NIT are experimental and normal intermediary toe spreading $(\mathrm{mm})$, respectively. In the normal value range $( \pm 11 \%), 0$ represents a totally normal paw and 100 represent a totally impaired paw.

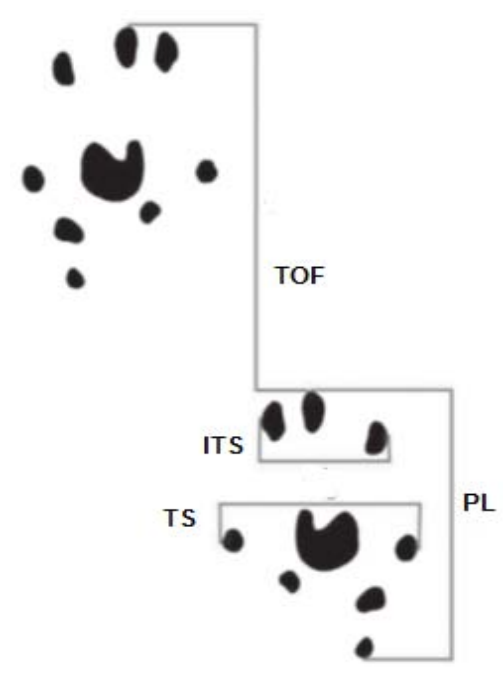

$\mathrm{X}$-ray radiographic assessment

On day 21 post-CFA injection, radiographs were taken with X-ray apparatus (PHILIPS Diagnose X-ray) at $55 \mathrm{kVp}$ and $3 \mathrm{~mA}$ with focal film distance of $60 \mathrm{~cm}$. The severity of joint deformation was blindly scored in accordance with the extent of oesteoporosis, joint spaces, soft tissue inflammation, subchondral erosion and joint ankylosis on 
a scale of $0-4$ as described by [10]; the scores are as follows: 0: no soft tissue inflammation and no degenerative joint changes; 1 : slight soft tissue inflammation, joint space, subchondral erosion, oesteolysis and degenerative joint changes, 2: moderate soft tissue inflammation, joint space, subchondral erosion, oesteolysis and degenerative joint changes; 3 : marked soft tissue inflammation, joint space, subchondral erosion, oesteolysis and degenerative joint changes; and 4: severe soft tissue inflammation, joint space, subchondral erosion, oesteolysis and degenerative joint changes. The X-ray images were analysed and scored independently by two certified radiologists who were blinded to the groups.

\section{Haematology profile}

On day 22 post-CFA injection, $4.5 \mathrm{ml}$ of blood was collected from each animal through cardiac puncture under mild anaesthesia with diethyl ether and placed in suitable blood collection tubes (BD Vacutainer $($ ). Haematological parameters including haemoglobin content (HGB), total red blood cell count (RBC), percent packed cell volume (\% PCV) and total white blood cell count (WBC) were evaluated immediately after blood sample collection by using an automated haematology analyser (Beckman Coulter Blood Analyser). Erythrocyte sedimentation rate (ESR) was determined using the Westergren capillary tube method described by Guha et al. (2014).

\section{Data analysis}

The data obtained from in vivo experiments were expressed as mean $\pm S E M$; while other data were expressed as mean \pm SD. Statistical difference between means was analysed by IBM-SPSS version 20 software by using one-way ANOVA followed by post hoc Dunnett- $t$ test (2-tailed) at different variance levels.

\section{RESULTS AND DISCUSSION}

\section{Selection of adsorbent}

The sticky, greasy texture of the M. oleifera extract requires the use of a suitable adsorbent to convert it into non-stick, freely flowable granules. Various adsorbents, natural or synthetic, were tested at the ratio of 1:1 to convert the M. oleifera extract into powder form (table 1). Three adsorbents showed a promising results, i.e. Avicel PH101, PVP-K12.5 and gum Arabic. For the three selected adsorbents, different ratios of adsorbents to the M. oleifera extract were tested (i.e. 0.5:1, 0.6:1 and 0.75:1) to determine the lowest useful ratio.

Table 1: Description of the granules when different adsorbents were mixed with $95 \%$ ethanol extract of $M$. oleifera leaf at 1:1 ratio

\begin{tabular}{ll}
\hline Adsorbent & Description \\
\hline Avicel PH 200 & Good shape coarse granules, dark green colour and need long drying time. \\
Avicel PH101 & Good shape green colour granules. \\
Lactose monohydrate & Sticky soft very dark green colour mass and cannot be shaped as granules. \\
Starch (maize) & Soft light green colour mass and cannot be shaped as granules. \\
$\beta$-cyclodextrin & Sticky soft dark green mass and cannot be shaped as granules. \\
PVP-K12.5 & Good shape green granules, hygroscopic during storage. \\
Gum Arabic & Good shape very dark green granules. \\
\hline
\end{tabular}

The prepared mixtures were evaluated for their flow properties and bulk and tapped densities (table 2). On the basis of the results of the angle of repose and density, gum Arabic was selected as the adsorbent to be applied at an adsorbent-to-M. oleifera extract ratio of 0.6:1.

Table 2: Evaluation of lowest ratio of adsorbents to M. oleifera extract for their flowability and density per adsorbent

\begin{tabular}{lllll}
\hline Adsorbent & Lowest ratio & Angle of repose & Bulk density & Tapped density \\
\hline Avicel PH101 & $0.6: 1$ & $30.191 \pm 0.083$ & $0.323 \pm 0.003$ & $0.3488 \pm 0.0667$ \\
Gum Arabic & $0.6: 1$ & $33.690 \pm 0.112$ & $0.4046 \pm 0.201$ & $0.4563 \pm 0.412$ \\
PVP-K12.5 & $0.75: 1$ & $37.364 \pm 0.0642$ & $0.3448 \pm 0.0938$ & $0.3726 \pm 0.113$ \\
\hline
\end{tabular}

*Results were expressed as (mean $\pm \mathrm{SD}, \mathrm{n}=3$ ).

\section{Selection of surfactant}

Different types of surfactants, anionic and non-ionic, (Poloxamer 407, sodium lauryl sulphate, Tween 20 , Tween 40 , Tween 80 , Span 20 and Span 40) were tested. Evaluation of the tested surfactants showed that Tween 20 was the best surfactant that improved the solubility of the M. oleifera extract. Tween 20 is a polyoxyethylene sorbitan monolaurate, that is, an amphipathic surfactants composed of fatty acid esters of polyoxyethylene sorbitan. Their popularity is largely due to their effectiveness at low concentrations and relatively low toxicities with an acceptable daily intake is up to $25 \mathrm{mg} / \mathrm{kg}$ body weight [12]. In addition, these surfactants are also widely used in the food industry because of their excellent emulsifying properties. Surfactant molecules form associates in the aqueous/non-aqueous solution beyond a certain concentration called micelles. The shape and size of the micelles are affected by many factors including temperature and concentration of surfactant. The consumption of missiles in the form of drug carriers is more valuable than other types of carriers owing to their tiny mass $(\sim 10-30 \mathrm{~nm})$ and the enhanced stability of the drug in the course of missiles inclusion [13]. Accordingly, Tween 20 was selected to be used in the formulation of Moringa-G. Different concentrations of Tween 20 were then tested to determine the lowest useful concentration, which turned out to be $1 \%(\mathrm{w} / \mathrm{w})$. Tween 20 was miscible with Moringa crude extract and other added excipients and can also improve bioavailability by acting as a P-glycoprotein inhibitor [14]. Identifying the solubility extent is important in determining the need for additional improvement steps.

\section{Preparation of Moringa granules}

On the basis of the results of the test adsorbents and surfactant agents above, gum Arabic was selected as adsorbent and Tween 20 was selected as surfactant for preparation of Moringa granules. The granules were prepared through wet granulation at a dose size of $3 \mathrm{~g} /$ dose as described by [8] to be the minimum effective dose. No need for adding preservative as ethanol extract of $M$. oleifera leaves was known for its antimicrobial activity against wide range of microorganisms [15]. In addition to that, usually alcoholic extract in contrast to aqueous extract does not need for preservatives or a stabilizer $[16,17]$.

\section{Organoleptic properties and physical characteristics of the prepared Moringa granules (Moringa-G)}

The prepared Moringa-G was evaluated for organoleptic properties, including appearance, colour, odour and taste (table 3). Particle size distribution was slightly wide in range due to the use of manual granulation.

Loss on drying as within the acceptable limit of USP37-NF32 (2014). The powder flowability test results, including angle of repose, Hausner's ratio and Carr's index, indicate the good flowability of the granules. 


\section{FT-IR spectroscopy of Moringa-G}

The FT-IR spectra of the $95 \%$ ethanol extract of M. oleifera leaves and the prepared Moringa-G showed the compatibility of the used excipients with the extract (fig. 1). All the major peaks of the $M$. oleifera extract and Moringa-G were present. The spectra did not show additional peaks, shifts or disappearance of characteristic peaks. This result confirms the absence of any chemical or physical interaction between the M. oleifera extract and excipients used for granule preparation.

Table 3: Organoleptic properties and physical characteristics for the prepared Moringa granules

\begin{tabular}{ll}
\hline Parameter & Result \\
\hline Appearance & Coarse granules not stick to container wall or aggregate together with acceptable shape \\
Colour & Very dark green \\
Odour & Faint characteristic odour \\
Taste & Slight bitter pungent taste \\
Particle size distribution & $3.6 \%: 700 \mu \mathrm{m}$ \\
& $79.4 \%: 500 \mu \mathrm{m}$ \\
& $11.6 \%: 350 \mu \mathrm{m}$ \\
& $4.5 \%: 210 \mu \mathrm{m}$ \\
Loss on drying (\%) at $65^{\circ} \mathrm{C}$ & $0.428 \%$ \\
pH of $5 \%$ aqueous solution at $25^{\circ} \mathrm{C}$ & 4.48 \\
Time of reconstitution & $50-60 \mathrm{~second}$ \\
Angle of repose & $33.690 \pm 0.112$ \\
Bulk density & $0.4206 \pm 0.201 \mathrm{~g} / \mathrm{cm}^{3}$ \\
Tapped density & $0.4563 \pm 0.412 \mathrm{~g} / \mathrm{cm}^{3}$ \\
Hausner's ratio & 1.1277 \\
Carr's index & $11.33 \%$ \\
\hline
\end{tabular}

*Results were expressed as (mean $\pm \mathrm{SD}, \mathrm{n}=3$ ).

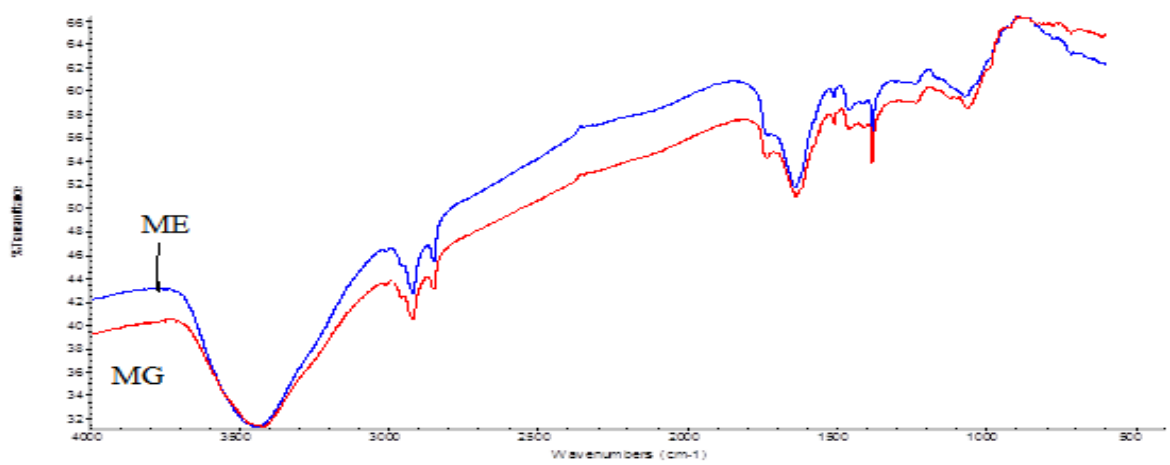

Fig. 1: FT-IR spectra of $95 \%$ ethanol extract of $M$. oleifera leaves (ME) and prepared Moringa granules (MG)

\section{Drug content of the prepared Moringa-G}

The drug content was determined using HPLC-UV method. The acceptance criterion of the initial concentration of the selected reference markers was $90 \%-110 \%$. The percent drug contents for the three reference markers, namely, cryptochlorogenic acid, isoquercetin and astragalin, were $100.326 \pm 1.783,99.631 \pm 1.322$ and $97.406 \pm 1.392$, respectively, which were equivalent to $3.555,19.593$ and $5.611 \mathrm{mg} / \mathrm{g}$ dry extract, respectively.

\section{In vitro dissolution test for the prepared Moringa-G}

The dissolution test of the preparedness Moringa-G revealed an improved dissolution rate and extent compared with the crude $M$. oleifera extract (fig. 2). The prepared Moringa granules showed increase in dissolution rate of cryptochlorogenic acid, isoquercetin and astragalin by $0.66,1.34$ and 1.23 folds respectively.

This improvement in the dissolution profile could be due to the surfactant agent (Tween 20) adopted in the formula. Moreover, the gum Arabic fine powder used as an adsorbent and the formulation of $M$. oleifera extract as granules led to an increase in the surface area of the extract that exposed to the dissolution medium, thereby increasing the solubility. A low drug solubility is expected to yield a low dissolution rate. Based on the Noyes-Whitney law, the dissolution rate $(d c / d t)$ is directly proportional to the concentration gradient $\left(C_{0}-C_{X}\right)$ and surface area.

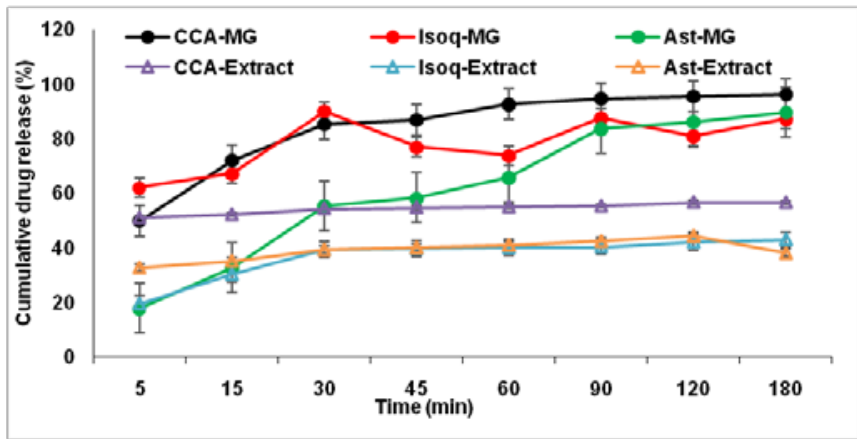

Fig. 2: In vitro drug release profile and dissolution rate of three reference markers present in prepared Moringa granules. Ast= astragalin; $\mathrm{CCA}=$ cryptochlorogenic acid and Isoq= isoquercetin. Data were presented as mean $\pm \operatorname{SD}(n=6)$ 


\section{Microbial limit tests of Moringa-G}

Table (4) shows the microbial limit tests for the formulated Moringa-G which appeared to be free of any microbial contaminating.

\section{Heavy metals tests for Moringa-G}

Heavy metals, including arsenic, cadmium, lead and mercury, in the formulated Moringa-G were determined through [7]. The results revealed a non-detectable level of testing heavy metals in the formulations (table 5). Hence, the suitability and safety of the formulated Moringa-G were confirmed.

\section{In vivo anti-inflammatory assay}

Animals in the groups treated orally with either indomethacin, 95\% ethanol extract of $M$. oleifera leaves, or Moringa-G significantly inhibited the increase in the paw thickness $(\mathrm{P}<0.05)$ compared with those in the control group (fig. 3). The oral administration of the
95\% ethanol extract of $M$. oleifera leaves showed less significant inhibition effect on the increase in the paw thickness $(\mathrm{P}<0.05)$ than Moringa-G. The effect of Moringa-G was comparable with that of indomethacin in terms of the extent and onset of activity. The oral administration of crude M. oleifera extract or Moringa-G began $2 \mathrm{~h}$ post-injection and continued until hour 5 post-injection. Formulation of Moringa crude extract as a granule lead up to improvement of the anti-inflammatory activity.

The higher extent of activity and the faster onset of action of Moringa-G than those of the crude M. oleifera extract were attributed to the effects of the formulation of the extract in its pharmaceutical dosage form. Formulating M. oleifera extract as granules led to higher solubility and enhanced absorption and bioactivity compared with crude M. oleifera extract. Finding of [18], who formulated aqueous M. oleifera leaf extract as film dressing for wound healing, and [19], who formulated M. oleifera leaf powder as tablet, reported improvements in the in vivo bioactivity of the extract after formulation.

Table 4: Microbial limit tests for the formulated Moringa granules

\begin{tabular}{llll}
\hline Microbial type & Result & Limit & Method \\
\hline Total aerobic microbial count (TAMC) & ND & $<10 \mathrm{CFU} / \mathrm{g}$ & BP 2013, Appendix XVIB \\
Total combined yeasts/moulds count (TYMC) & ND & $<10 \mathrm{CFU} / \mathrm{g}$ & BP 2013, Appendix XVIB \\
Bile-tolerant gram-negative bacteria & ND & $<10 \mathrm{PN} / \mathrm{g}$ & BP 2013, Appendix XVIB \\
Salmonella sp. & Absent & in 10 g & \\
Escherichia coli & Absent & in 1 g & BP 2013, Appendix XVIB \\
Staphylococcus aureus & Absent & in 1 g & BP 2013, Appendix XVIB \\
Pseudomonas aeruginosa & Absent & in 1 g & BP 2013, Appendix XVIB BP 2013, Appendix XVIB \\
\hline
\end{tabular}

*ND: not detected and BP: British Pharmacopoeia

Table 5: Heavy metals tests for detection of arsenic, cadmium, lead and mercury levels in the formulated Moringa granules

\begin{tabular}{llll}
\hline Heavy metal & Result & Limit & Method \\
\hline Arsenic & ND & $<0.1 \mathrm{mg} / \mathrm{kg}$ & BP 2013, Appendix IID, ICP-AES \\
Cadmium & ND & $<0.1 \mathrm{mg} / \mathrm{kg}$ & BP 2013, Appendix IID, ICP-AES \\
Lead & ND & $<0.1 \mathrm{mg} / \mathrm{kg}$ & BP 2013, Appendix IID, ICP-AES \\
Mercury & ND & $<0.1 \mathrm{mg} / \mathrm{kg}$ & BP 2013, Appendix IID, ICP-AES \\
\hline
\end{tabular}

*ND: not detected and BP: British Pharmacopoeia.

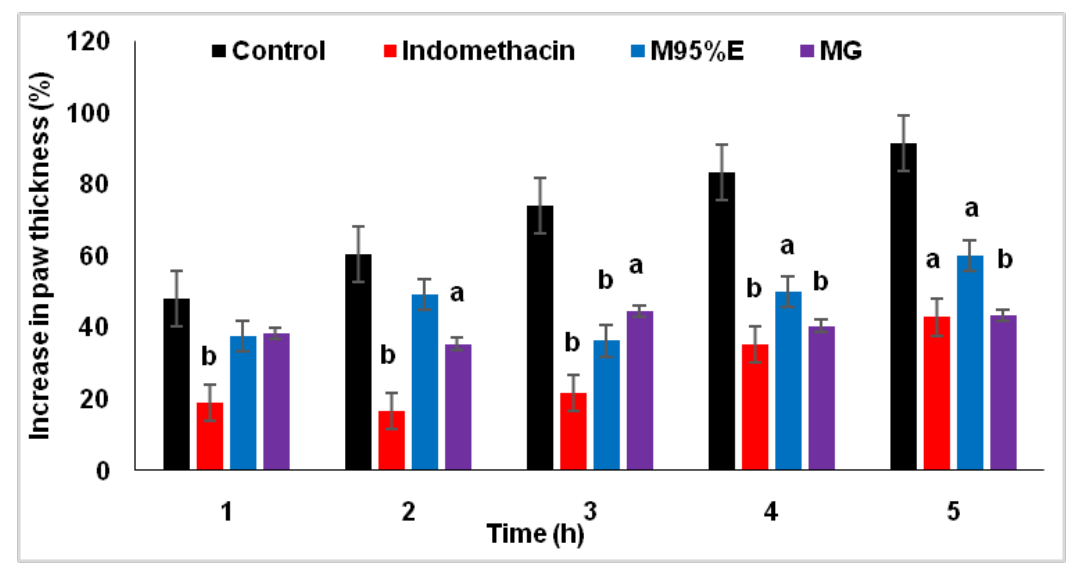

Fig. 3: Effect of oral administration of $95 \%$ ethanol M. oleifera leaves, indomethacin, and Moringa granules on carrageenan-induced hind paw oedema in rats. a: significant difference at $P<0.05$ and $b$ : significant difference at $P<0.01$. Data were presented as mean $\pm S E M$ for number of animals $n=6$

\section{Effect of formulated Moringa-G on the paw thickness of rats}

Oral administration of indomethacin, 95\% ethanol extract of $M$. oleifera leaves, and Moringa-G significantly inhibited the increase in the paw thickness of rats with $C F A$-induced arthritis $(\mathrm{P}<0.05)$ compared with that in the CFA-control group (fig. 4). Based on statistical data analysis, the effect of Moringa-G was comparable with that of indomethacin. Furthermore, Moringa-G was generally more effective in inhibiting the increase in the paw thickness than Moringa crude extract. 


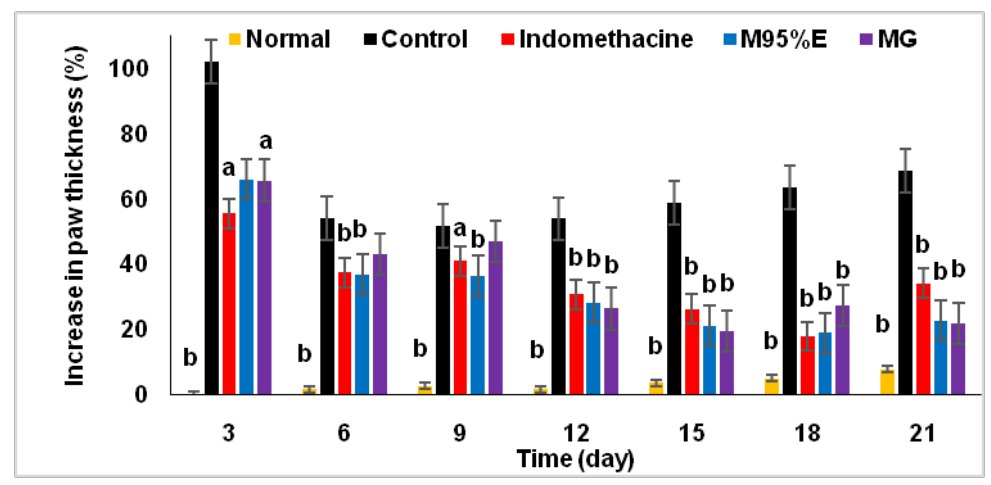

Fig. 4: Effect of oral administration of indomethacin, $95 \%$ ethanol extract of $M$. oleifera leaves, and Moringa granules on percent increase in paw thickness for CFA-induced arthritis rats. a: significant difference at $P<0.05$ and b: significant difference at $P<0.01$. Data were presented as mean \pm SEM for number of animals $(\mathrm{n})=6$

\section{Effect of Moringa-G on the body weight of rats}

Oral administration of $95 \%$ ethanol extract of $M$. oleifera leaves significantly increased the body weight of the animals $(\mathrm{P}<0.05)$ compared with that in the CFA-control group (fig. 5). Oral administration of indomethacin at $2.5 \mathrm{mg} / \mathrm{kg} /$ day and Moringa-G at dose equivalent to $250 \mathrm{mg} / \mathrm{kg} /$ day increased the body weight, but the effect was not significant. Rats in the normal group showed a steady increase in body weight. Rats in the group orally treated with crude M. oleifera extract showed higher percent weight gain than those in the normal group.

This result could be due to the high nutritional value and contents of essential amino acids and vitamins in the M. oleifera leaf extract. The insignificant increase in the body weight of rats in the group treated orally with indomethacin may be due to the adverse ulcerative and gastric disturbance effects associated with indomethacin [19]. For the rats treated with Moringa-G, the decrease in the body weight at the first $6 \mathrm{~d}$, and the insignificant increase could be due to the effect of gum Arabic in reducing body weight and fat level [21].

\section{Arthritic index}

Oral administration of indomethacin at $2.5 \mathrm{mg} / \mathrm{kg} / \mathrm{day}, 95 \%$ ethanol extract of M. oleifera leaves at dose $250 \mathrm{mg} / \mathrm{kg} /$ day, and Moringa-G at dose equivalent to $250 \mathrm{mg} / \mathrm{kg} /$ day significantly decreased the arthritic scores $(\mathrm{P}<0.05)$ compared with that in the CFA-control group (fig. 6). The animal group orally treated with Moringa-G achieved the lowest arthritic scores, i.e. less severe clinical signs of inflammation and arthritis, than the animal groups given with indomethacin and crude M. oleifera extract.

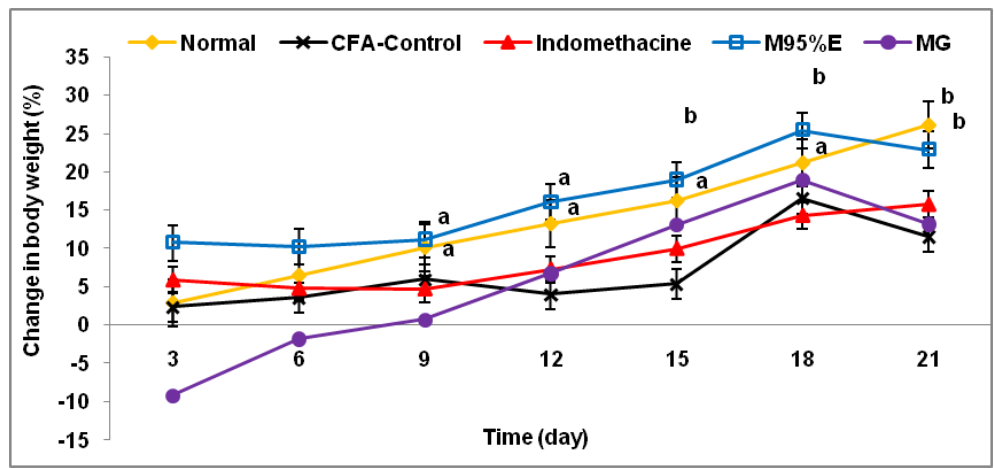

Fig. 5: Effect of oral administration of indomethacin, $95 \%$ ethanol extract of $M$. oleifera leaves, Moringa granules on percent increase in body weight for CFA-induced arthritis rats. a: significant difference at $\mathrm{P}<0.05$ and b: significant difference at $P<0.01$. Data were presented as mean $\pm S E M$ for number of animals $(n)=6$

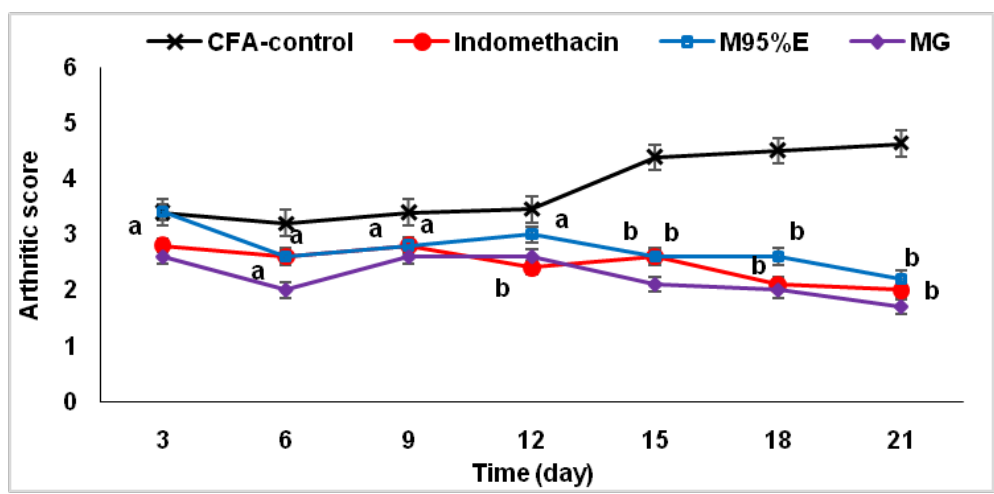

Fig. 6: Effect of oral administration of indomethacin, $95 \%$ ethanol extract of $M$. oleifera leaves, and Moringa granules on arthritic index of CFA-induced immunological arthritis rats. a: significant at $P<0.05$ and b: significant at $P<0.01$. Data were presented as mean $\pm S E M$ for number of animals $(\mathrm{n})=6$ 


\section{Walking track analysis using deMedinaceli method}

Rats with CFA-induced arthritis treated orally with indomethacin at $2.5 \mathrm{mg} / \mathrm{kg} /$ day, $95 \%$ ethanol extract of $M$. oleifera leaves at 250 $\mathrm{mg} / \mathrm{kg} /$ day, and Moringa-G at dose equivalent to $250 \mathrm{mg} / \mathrm{kg} /$ day exhibited functional index within the normal range $( \pm 11 \%)$ on day 21 (table 6). However, the CFA-control group showed an out of normal values after $3 \mathrm{w}$ of CFA injection. Hence, Moringa-SD prevented the disruption of locomotion and gait behaviour.

\section{$\mathrm{X}$-ray radiography assessment}

In the CFA-control group, soft tissue swelling (white arrows) and reduced joint spaces (black arrows) were observed, indicating the narrowing of the joint space under arthritic conditions (fig. 7). The average radiographic score for the CFA-control group $(n=6)$ on day 22 post CFA injection was $9.66 \pm 1.16$. Groups given indomethacin at $2.5 \mathrm{mg} / \mathrm{kg} / \mathrm{day}$, 95\% ethanol extract of M. oleifera leaves at dose of $250 \mathrm{mg} / \mathrm{kg} /$ day, and Moringa-G at dose equivalent to 250 $\mathrm{mg} / \mathrm{kg} /$ day for $21 \mathrm{~d}$ exhibited average radiographic scores of
$3.17 \pm 1.08,3.23 \pm 1.21$, and $3.30 \pm 1.24$, respectively. Statistical data analysis of the obtained scores (mean \pm SEM) revealed that $21 \mathrm{~d}$ of oral treatment with indomethacin, $95 \%$ ethanol extract of M. oleifera leaves, formulated Moringa- $G$ significantly reduced $(\mathrm{P}<0.01)$ the radiographic score of rats with CFA-induced arthritis.

\section{Haematology profile}

All of the animals in the treatment groups and the normal control group were evaluated for haematological parameters including the HGB, total RBC, \%PCV, total WBC and ESR (table 7). The erythrocyte profile of rats in the CFA-control group was below the normal value ranges. These abnormal results suggest the occurrence of iron deficiency anaemia, which is a clinical manifestation of RA. The erythrocyte profiles of rats in all of the orally treated groups were comparable with those in the normal group but significantly different $(\mathrm{P}<0.05)$ from those in the $\mathrm{CFA}$-control group. These results could be due to enhanced solubility of phytonutrients in the M. oleifera extract and the consequent improvement in absorption.

Table 6: Effects of oral administration of indomethacin $2.5 \mathrm{mg} / \mathrm{kg} / \mathrm{d}, 95 \%$ ethanol extract of $M$. oleifera leaves $250 \mathrm{mg} / \mathrm{kg} / \mathrm{d}$, and $M o r i n g a$ granules on functional index of CFA-induced arthritis rats

\begin{tabular}{llll}
\hline Group & Day 0 & Day 14 & Day 21 \\
\hline CFA-control & $1.67 \pm 1.51$ & $-1.41 \pm 1.99$ & $-18.22 \pm 6.19$ \\
Indomethacin & $-4.11 \pm 1.92$ & $-1.55 \pm 6.12$ & $-5.88 \pm 2.60$ \\
M95\%E & $-1.80 \pm 4.43$ & $-3.06 \pm 4.27$ & $-1.38 \pm 3.87$ \\
Moringa granules & $2.23 \pm 2.45$ & $-16.55 \pm 2.78$ & $-7.89 \pm 2.16$ \\
\hline
\end{tabular}

${ }^{*}$ Results were expressed as (mean \pm SEM, $\left.n=6\right)$.
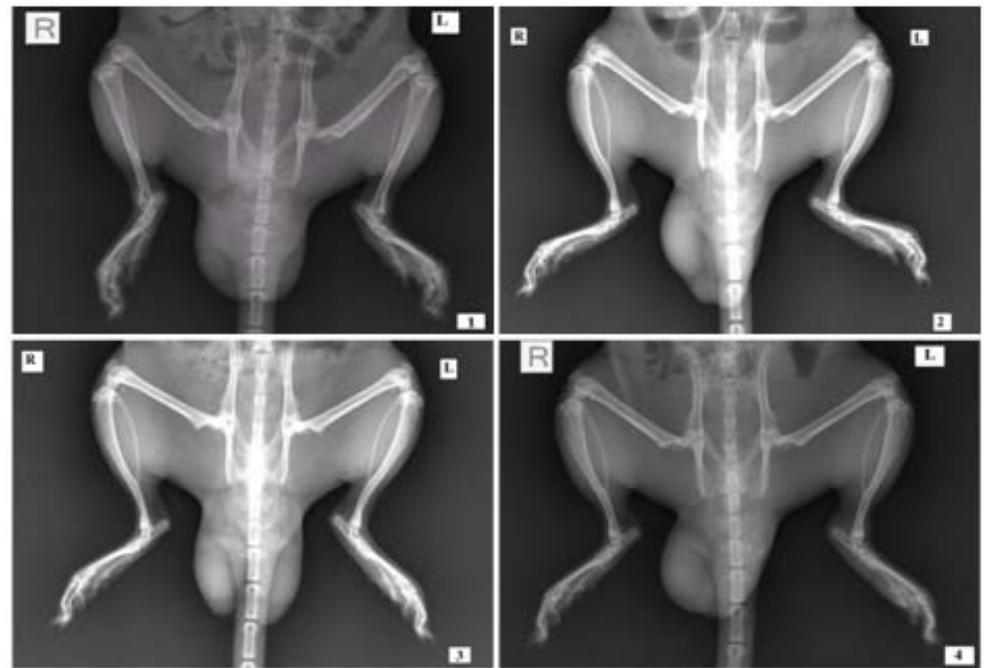

Fig. 7: X-ray radiographs for hind paws of CFA-induced arthritis rats at day 22 post CFA injection. 1: CFA-induced arthritis rat without treatment, 2: animal orally treated with indomethacin at dose $2.5 \mathrm{mg} / \mathrm{kg} / \mathrm{day}$, 4: animal orally treated with $95 \%$ ethanol extract of $M$. oleifera leaves at dose $250 \mathrm{mg} / \mathrm{kg} / \mathrm{day}$ and 5 : animal orally treated with Moringa granules at dose equivalent to $250 \mathrm{mg} / \mathrm{kg} / \mathrm{day}$

Table 7: Effects of oral administration of indomethacin, $95 \%$ ethanol extract of $M$. oleifera leaves, and formulated $M$ Moringa granules on haemoglobin content (HGB), total red blood cell count (RBC), \% packed cell volume (\%PCV), total white blood cells count (WBC) and erythrocyte sedimentation rate (ESR) in CFA-induced arthritis rats; results were expressed as $\mathbf{m e a n} \pm$ SEM and $n=6$

\begin{tabular}{|c|c|c|c|c|c|c|}
\hline \multirow{2}{*}{$\begin{array}{l}\text { Haematology } \\
\text { parameter }\end{array}$} & \multirow[t]{2}{*}{ Normal range } & \multicolumn{5}{|l|}{ Animal group } \\
\hline & & Healthy rats & CFA-Control & Indomethacin & M95\%E & MG \\
\hline HGB (g/dl) & $13.5-18.4^{*}$ & $13.60 \pm 0.15^{\mathrm{a}}$ & $12.25 \pm 0.79$ & $13.30 \pm 0.45^{\mathrm{a}}$ & $13.87 \pm 0.36^{b}$ & $13.65 \pm 0.74^{a}$ \\
\hline PCV $(\%)$ & $38.9-54.9^{*}$ & $39.50 \pm 0.01^{\mathrm{a}}$ & $35.75 \pm 0.02$ & $39.50 \pm 0.02^{a}$ & $41.0 \pm 0.01^{b}$ & $39.75 \pm 0.17 \mathrm{a}$ \\
\hline $\mathrm{RBC}(10[12] / 1)$ & $7.8-10.2^{*}$ & $7.86 \pm 0.09^{b}$ & $7.08 \pm 0.39$ & $7.83 \pm 0.37^{a}$ & $7.95 \pm 0.23^{\mathrm{a}}$ & $7.62 \pm 0.25^{a}$ \\
\hline WBC $\left(10^{9} / 1\right)$ & $5.9-19.0^{*}$ & $9.70 \pm 2.19 \mathrm{a}$ & $12.59 \pm 0.54$ & $7.75 \pm 1.22^{b}$ & $9.76 \pm 0.74$ & $10.48 \pm 0.24$ \\
\hline $\operatorname{ESR}(\mathrm{mm} / \mathrm{h})$ & $0.5-1.45^{* *}$ & $1.12 \pm 0.13^{\mathrm{a}}$ & $2.04 \pm 0.04$ & $0.45 \pm 0.05^{b}$ & $0.84 \pm 0.12^{\mathrm{b}}$ & $1.01 \pm 0.09 \mathrm{~b}$ \\
\hline
\end{tabular}

MG: Moringa granules; M95\%E: 95\% ethanol extract of M. oleifera leaf; *: normal range in rats according to Petterino and Argentino-Storino (2006); **: normal range in rats according to Ihedioha et al. (2017); a: significant at $P<0.05$ and b: significant at $P<0.01$ compared to CFA-control group, * Results were expressed as (mean \pm SEM, $n=6$ ). 
The CFA-control group showed the highest WBC level, which is still within the normal range. The groups orally given indomethacin at $2.5 \mathrm{mg} / \mathrm{kg} /$ day showed a significant difference $(\mathrm{P}<0.05)$ in WBC compared with the CFA-control group. By contrast, the oral administration of crude extract of $M$. oleifera leaves and Moringa-G at dose equivalent to $250 \mathrm{mg} / \mathrm{kg} /$ day did not significantly affect the WBC compared with that in the CFA-control group.

Rats with CFA-induced arthritis treated orally with indomethacin at $2.5 \mathrm{mg} / \mathrm{kg} /$ day, $95 \%$ ethanol extract of $M$. oleifera leaves at 250 $\mathrm{mg} / \mathrm{kg} / \mathrm{d}$, or Moringa $-\mathrm{G}$ at dose equivalent to $250 \mathrm{mg} / \mathrm{kg}$ showed significant decreases in the ESR $(\mathrm{P}<0.05)$ compared with rats in the CFA-control group.

\section{CONCLUSION}

In some cases processing of natural source products may effects on bioactivity of the final product, therefore, material processing was evaluated to ensure a consistent level of bioactivity. The main challenge in the formulation of herbal products is the complex nature of its constituents and the scarcity of fundamental information about the physical and chemical properties of plant extracts. The formulation of $M$. oleifera leaf extract as a standardised granule effectively improved their physical and chemical properties, particularly flowability, crystallinity degree, aqueous solubility, drug release profile and stability under stress conditions. In comparison with crude Moringa extract, the formulation of $95 \%$ ethanol extracts of Moringa leaves as a common granules improved their in vivo bioactivity. Haematological tests, body weight gain and arthritic index also indicated that the admissibility and health improvement induced symptoms of arthritis could be alleviated by the formulated Moringa extract were better than those promoted by to a greater extent than crude Moringa extract.

\section{ACKNOWLEDGMENT}

The authors acknowledge Vet Dr Ng Yeong Sheng, Hope Veterinary Centre for his assistance in X-ray radiography. They would also like to thank Mr Rosli Hassan, Chief Lab. Assis-tant, Discipline of Pharmacology, School of Pharmaceutical Sciences, USM and Dr Saifullahi Abubakar for their cooperation and help in monitoring and in the evaluation of animals disease development.

\section{FUNDING}

Nil

\section{AUTHORS CONTRIBUTIONS}

Dr. Harith Jameel, the guarantor of this study, has designed, carried out the experiment, analyzed the results, and contributed in the preparation and revision of the manuscript. Assciate Prof Dr. Nurzalina Abdul Karim and Associate Prof Dr Roziahanim Mahmudhave designed, supervised the experimental process, and reviewed the manuscript.

\section{CONFLICT OF INTERESTS}

The authors declare no conflict of interest.

\section{REFERENCES}

1. Monera PTG, Jani ZT, Maponga CC, Mudzengi J, Morse GD, Nhachi CFB. Quality and labeling information of Moringa oleifera products marketed for HIV-infected people in Zimbabwe. J Public Health Afr 2016;7:84-92.

2. Pahwa R, Kataria U, Rana AC, Rao R, Nanda S. Solid dispersion technology: recent advancements in the delivery of various phytoconstituents. Int J Pharm Sci Res 2015;6:510-24.

3. Favor CC. A review on the nutritive value of dilis (Encrasicholina oligobranchus, wongratana, 1983) powder and malungay (Moringa oleifera lam.) leaves powder, as potential food supplement. J Crit Rev 2020;7:1975-8.

4. Saavedra Y, Maden VDE. Opportunities for development of the Moringa sector in bangladesh: desk-based review of the moringa value chains in developing countries and end-markets in Europe; 2015. Available from: http://edepot.wur.nl/364740 [Last accessed on 05 Nov 2020]

5. Alsammarraie HJM, Khan NAK, Asmawi MZ, Mahmud R, Murugaiyah V. Preformulation, stress stability studies and HPLC-UV method development and validation for $95 \%$ ethanol extract of Moringa oleifera lam. Leaves. Bull Fac Pharm Cairo Univ 2019;57:114-26.

6. USP37-NF32. United States Pharmacopeia and National Formulary (USP 37-NF32, 2014), General tests and assays, Physical tests and determenations, $<621>$ Chromatography; 2014.

7. British Pharmacopoeia, London, the stationary office; 2009. p 3921-22.

8. Mahdi HJ, Khan NAK, Asmawi MZ, Mahmud R, Murugaiyah V. In vivo anti-arthritic and anti-nociceptive effects of ethanol extract of Moringa oleifera leaves on complete Freund's adjuvant (CFA)-induced arthritis in rats. Integ Med Res 2018;7:85-94.

9. Nair V, Singh S, Gupta YK. Evaluation of disease modifying activity of Coriandrum sativum in experimental models. Indian J Med Res 2012;135:240-51.

10. Vijayalaxmi A, Bakshi V, Begum N. Anti-arthritic and anti inflammatory activity of beta caryophyllene against freund's complete adjuvant induced arthritis in wistar rats. Bone Rep Recom 2015;1 Suppl 2:1-10.

11. de Medinaceli L, Wyatt RJ, Freed WJ. Peripheral nerve reconnection: mechanical, thermal, and ionic conditions that promote the return of function. Exper Neurol 1983;81:469-87.

12. Heinze T, Liebert T. Celluloses and polyoses/hemicelluloses. In: Polymer science: a comprehensive reference. New York: Elsevier; 2012. p. 83-152.

13. Li L, Ni R, Shao Y, Mao S. Carrageenan and its applications in drug delivery. Carbo Poly 2014;103:1-11.

14. Srivalli KMR, Lakshmi PK. Overview of P-glycoprotein inhibitors: a rational outlook. Brazilian J Pharm Sci 2012;48:353-67.

15. Leone A, Spada A, Battezzati A, Schiraldi A, Aristil J, Bertoli S. Cultivation, genetic, ethnopharmacology, phytochemistry and pharmacology of Moringa oleifera leaves: an overview. Int J Mol Sci 2015;16:12791-835

16. Iwu MM, Wootton JC. Advances in phytomedicine: ethnomedicine and drug discovery. Amsterdam: Elsevier; 2002. p. 123-36.

17. Uphadek B, Shinkar DM, Patil PB, Saudagar RB. Moringa oleifera as a pharmaceutical excipient. Int J Curr Pharma Res 2018;10:13-6.

18. Chin CY, Jalil J, Ng PY, Ng SF. Development and formulation of Moringa oleifera standardised leaf extract film dressing for wound healing application. J Ethnopharm 2018;212:188-99.

19. Zheng Y, Zhu F, Lin D, Wu J, Zhou Y, Mark B. Optimization of formulation and processing of Moringa oleifera and Spirulina complex tablets. Saudi J Biol Sci 2017;24:122-6.

20. Mayo SA, Song YK, Cruz MR, Phan TM, Singh KV, Garsin DA, et al. Indomethacin injury to the rat small intestine is dependent upon biliary secretion and is associated with overgrowth of enterococci. Physiol Reports 2016;4:e12725.

21. Babiker R, Merghani TH, Elmusharaf K, Badi RM, Lang F, Saeed AM. Effects of gum arabic ingestion on body mass index and body fat percentage in healthy adult females: two-arm randomized, placebo controlled, double-blind trial. Nut J 2012;11:111-22. 